\title{
Amniotic fluid stem cells morph into a cardiovascular lineage: analysis of a chemically induced cardiac and vascular commitment
}

This article was published in the following Dove Press journal:

Drug Design, Development and Therapy

26 September 2013

Number of times this article has been viewed

\author{
Margherita Maioli'-3 \\ Giovanni Contini' \\ Sara Santaniello ${ }^{1,2}$ \\ Pasquale Bandiera' \\ Gianfranco Pigliaru' ${ }^{1,2}$ \\ Raimonda Sanna ${ }^{5}$ \\ Salvatore Rinaldi ${ }^{3}$ \\ Alessandro P Delitala' \\ Andrea Montella ${ }^{1,5}$ \\ Luigi Bagella ${ }^{1,6}$ \\ Carlo Ventura ${ }^{2-4}$
}

'Department of Biomedical Sciences, University of Sassari, Sassari,

${ }^{2}$ Laboratory of Molecular Biology and Stem Cell Engineering, National Institute of Biostructures and Biosystems, Bologna, ${ }^{3}$ Department of Regenerative Medicine, Rinaldi Fontani Institute, Florence, ${ }^{4} \mathrm{Cardiovascular}$ Department, S Orsola-Malpighi Hospital, University of Bologna, Bologna, ${ }^{5}$ Facility of Genetic and Developmental Biology, AOU Sassari, Sassari, Italy; 'S Sbarro Institute for Cancer Research and Molecular Medicine, Center for Biotechnology, College of Science and Technology, Temple University, Philadelphia, PA, USA

Correspondence: Luigi Bagella Department of Biomedical Sciences, Division of Biochemistry, University of Sassari, Viale San Pietro 43/b, 07100 Sassari, Italy

Tel +39079 228274

$\mathrm{Fax}+39079228120$

Email Ibagella@uniss.it

Salvatore Rinaldi

Rinaldi Fontani Institute, Viale

Belfiore 43, $50 \mathrm{I} 44$ Florence, Italy

Tel +39055290307

Fax +39055 290399

Email srinaldi@irf.it

\begin{abstract}
Mouse embryonic stem cells were previously observed along with mesenchymal stem cells from different sources, after being treated with a mixed ester of hyaluronan with butyric and retinoic acids, to show a significant increase in the yield of cardiogenic and vascular differentiated elements. The aim of the present study was to determine if stem cells derived from primitive fetal cells present in human amniotic fluid (hAFSCs) and cultured in the presence of a mixture of hyaluronic (HA), butyric (BU), and retinoic (RA) acids show a higher yield of differentiation toward the cardiovascular phenotype as compared with untreated cells. During the differentiation process elicited by exposure to $\mathrm{HA}+\mathrm{BU}+\mathrm{RA}$, genes controlling pluripotency and plasticity of stem cells, such as Sox2, Nanog, and Oct4, were significantly downregulated at the transcriptional level. At this point, a significant increase in expression of genes controlling the appearance of cardiogenic and vascular lineages in HA + BU + RA-treated cells was observed. The protein expression levels typical of cardiac and vascular phenotypes, evaluated by Western blotting, immunofluorescence, and flow cytometry, were higher in hAFSCs cultured in the presence of $\mathrm{HA}+\mathrm{BU}+\mathrm{RA}$, as compared with untreated control cells. Appearance of the cardiac phenotype was further inferred by ultrastructural analysis using transmission and scanning electron microscopy. These results demonstrate that a mixture of $\mathrm{HA}+\mathrm{BU}+\mathrm{RA}$ significantly increased the yield of elements committed toward cardiac and vascular phenotypes, confirming what we have previously observed in other cellular types.
\end{abstract}

Keywords: fetal cells, human amniotic fluid, hyaluronic acid, butyric acid, retinoic acid, prodynorphin, Nkx-2.5, GATA-4, von Willebrand factor

\section{Introduction}

Mesenchymal stem cells have generated a great deal of excitement as a potential source of cells for cell-based therapeutic strategies to promote regeneration of injured heart muscle. ${ }^{1-3}$ Their most interesting characteristic is that they may be directly obtained from individual patients, avoiding the complications associated with immune rejection of allogeneic cells. Tissue engineering-based therapies using autologous stem cells can represent a tool to create cardiac constructs for repairing injured hearts, although identification of an ideal source of immature cells capable of differentiating into cell lineages still represents a challenge. In this regard, stem cells derived from primitive fetal cells present in human and mouse amniotic fluid (hAFSCs) appear to have many of the key therapeutic benefits of embryonic stem cells while avoiding their ethical, medical, and logistical drawbacks. ${ }^{4}$ Some authors have previously described specific cardiomyogenic and vascular commitment of hAFSCs in vitro and cardiovascular structures when transplanted in models of heart injury in different species. ${ }^{5-8}$ However, although mesenchymal 
stem cells may be committable to cardiovascular lineages, it is well established that this differentiation process occurs with a very low yield. Hence, enabling high-throughput of cardiogenesis and vasculogenesis in hAFSCs would have obvious therapeutic potential.

In previous work, we used a mixed ester of hyaluronan with butyric and retinoic acids (HBR) acting as a differentiating agent. ${ }^{9,10}$ This compound was able to increase the yield of cardiomyocytes derived from mouse GTR1 embryonic stem cells ${ }^{9}$ and human mesenchymal stem cells isolated from bone marrow and alternative sources, including the dental pulp and fetal membranes of term placenta (FMhMSCs), ${ }^{10}$ the latter showing a higher yield of cardiovascular differentiation. More recently, it was observed that a mixture of hyaluronic acid (HA), butyric acid (BU), and retinoic acid (RA) resulted in optimization of graft revascularization after islet/stem cell intrahepatic cotransplantation in syngeneic diabetic rats, with better survival of transplanted tissue. ${ }^{11}$ The aim of the present study was to evaluate the effects of a combination of HA, $\mathrm{BU}$, and RA on cardiogenic and angiogenic differentiation of hAFSCs as we had previously observed ${ }^{9,10}$ in other types of mouse and human stem cells, and if these processes occur with a high yield.

Results obtained from immunofluorescence showed the mixture of $\mathrm{HA}+\mathrm{BU}+\mathrm{RA}$ to be most effective in inducing the appearance of a cardiovascular phenotype compared with combinations of $\mathrm{HA}+\mathrm{BU}, \mathrm{HA}+\mathrm{RA}$, or BU + RA.

\section{Materials and methods}

\section{Preparation of amniotic fluid-derived stem cells}

Amniotic fluid-derived stem cells were obtained from amniocenteses performed during six consecutive pregnancies for routine prenatal diagnosis at 15-18 weeks' gestation at Clinica Ginecologica, Università di Sassari. All the pregnant women, aged 30-40 years, gave their written consent for the study, which was accepted by the local ethics committee (Comitato di Bioetica, Sassari, Italy $\mathrm{N}^{\circ} 1098 / \mathrm{L}$ ). None of the participants were affected by chronic disease and were not taking any medications. The technique described by De Coppi et $\mathrm{al}^{4}$ was used to isolate hAFSCs c/kit+. Briefly, confluent amniotic fluid stem cell cultures were expanded for obtaining single cell suspensions by gentle trypsinization (trypsinNA-EDTA solution, Invitrogen, Carlsbad, CA, USA). The hAFSCs were immunomagnetically sorted for c/kit using a monoclonal anti-c/kit (CD117) antibody (Miltenyi Biotech, Minneapolis, MN, USA) directly conjugated to microBeads (Miltenyi Biotech) and then expanded in subconfluent conditions in Alpha Mem medium (Invitrogen) containing $15 \%$ fetal bovine serum (Invitrogen), 20\% Chang medium C (Chang B plus Chang C; Irvine Scientific, Santa Ana, CA, USA), $1 \%$ glutamine, and $1 \%$ penicillin/streptomycin. Singlecell derived amniotic fluid stem cell clones were established by limiting dilution as previously described. ${ }^{12}$ At least four different clones obtained from the same sample were tested. When the cells reached confluence, they were subcultured in $\mathrm{T} 25 \mathrm{~cm}^{2}$ flasks (BD Biosciences, San Jose, CA, USA) in the same medium. All cells used for experimentation were not frozen and were treated between passages 4 and 8 .

\section{Flow cytometry analysis}

Flow cytometry analysis was used to characterize the isolated hAFSCs and to evaluate specific antigen markers. Cells were harvested by treatment with $0.08 \%$ trypsin-EDTA and incubated with $1 \mu \mathrm{g} / 10^{6}$ cells of fluorophor-conjugated antibodies for 40 minutes at $4^{\circ} \mathrm{C}$ in the dark. The antibodies used were CD29 (PE-Cy5-conjugated), CD31 (PE-conjugated), CD34 (PE-conjugated), CD44 (fluorescein isothiocyanate [FITC]conjugated), and CD45 (FITC-conjugated), all sourced from BD Pharmingen (San Jose, CA, USA), CD90 (FITCconjugated) from BD Biosciences (San Jose, CA, USA), CD105 (PE-conjugated) from R\&D (Minneapolis, MN, USA), and CD133 (PE-conjugated) from Miltenyi Biotec. After washing, the cells were analyzed on a flow cytometer (FACSAria, BD Biosciences) by collecting 10,000 events, and data were analyzed using FACSDiva software (BD Biosciences). The hAFSCs used in this study were stained positive for CD90, CD105, CD44, and CD29, Oct4, Sox2, and Nanog, antigens typical of mesenchymal stem cells, and negative for CD34, CD133, and CD45.

Flow cytometry was also used to assess the percentage of hAFSCs expressing specific cell phenotype markers. For this reason, cells ( $1 \mu \mathrm{g} / 10^{6}$ cells $)$ were cultured in the absence or presence of HA + BU + RA for 10 days. These cells were also cultured in the absence or presence of HA $2 \mathrm{mg} / \mathrm{mL}+\mathrm{BU} 5 \mathrm{mM}$, or HA $2 \mathrm{mg} / \mathrm{mL}+\mathrm{RA} 1 \mu \mathrm{M}$, or BU $5 \mathrm{mM}+\mathrm{RA} 1 \mu \mathrm{M}$; after a fixation/permeabilization step, the cells were incubated with a primary antibody directed against $\alpha$-sarcomeric actinin (Sigma-Aldrich, St Louis, MO, USA), $\alpha$-myosin heavy chain (Santa Cruz Biotechnologies Inc, Santa Cruz, CA, USA), or von Willebrand factor (Abcam, Cambridge, MA, USA) for one hour at $4^{\circ} \mathrm{C}$, and with $1 \mu \mathrm{g}$ of FITC-conjugated secondary antibody (Santa Cruz Biotechnologies Inc) for one hour at $4^{\circ} \mathrm{C}$ in the dark. After washing, the cells were analyzed on the FACSAria flow cytometer by collecting 10,000 
events, and the data were analyzed using the FACSDiva software.

\section{Differentiation of hAFSCs towards a cardiovascular phenotype}

To induce cardiogenesis, human hAFSCs isolated from six donors were separately cultured in ultralow attachment plates for 2 days. On day 3, the cells were transferred to six-well tissue culture plates for an additional 7 days. hAFSCs were seeded at 8,000 cells $/ \mathrm{cm}^{2}$ in Alpha Mem medium containing $15 \%$ fetal bovine serum, $20 \%$ Chang medium containing $\mathrm{HA} 2 \mathrm{mg} / \mathrm{mL}$, BU $5 \mathrm{mM}$, and RA $1 \mu \mathrm{M}$ (all purchased from Sigma-Aldrich). The cells were also treated with $\mathrm{HA}+\mathrm{BU}$, $\mathrm{HA}+\mathrm{RA}$, or BU + RA. Control cells were cultured in Alpha Mem medium containing 15\% fetal bovine serum and 20\% Chang medium C. HA, BU, and RA were dissolved in water and added every 24 hours.

\section{Gene expression analysis}

Total RNA was isolated from cells cultured for 24,48 , and 72 hours, and at 7 and 10 days in the absence or presence of $\mathrm{HA}+\mathrm{BU}+\mathrm{RA}$, using Trizol reagent according to the manufacturer's instructions (Invitrogen). Total RNA was dissolved in RNase-free water and, for real-time polymerase chain reaction (PCR), cDNA was synthesized in a $50 \mu \mathrm{L}$ reaction volume with $1 \mu \mathrm{g}$ of total RNA and M-MLV reverse transcriptase according to the manufacturer's instructions (Invitrogen). Quantitative real-time PCR was performed using an iCycler Thermal Cycler (Bio-Rad, Hercules, CA, USA). Two microliters of cDNA were amplified in $50 \mu \mathrm{L}$ reactions using Platinum Supermix UDG (Invitrogen), $200 \mathrm{nM}$ of each primer, $10 \mathrm{nM}$ fluorescein (BioRad), and Sybr Green. After an initial denaturation step at $94^{\circ} \mathrm{C}$ for 10 minutes, temperature cycling was initiated. Each cycle consisted of $94^{\circ} \mathrm{C}$ for 15 seconds, $55^{\circ} \mathrm{C}-59^{\circ} \mathrm{C}$ for 30 seconds, and $60^{\circ} \mathrm{C}$ for 30 seconds, the fluorescence being read at the end of this step. Primers used for analysis of cardiogenesis (Prodynorphin, GATA-4, NKX-2.5, cardiac troponin T, alpha myosin heavy chain, Tbx-5, Mef2C $\alpha$-sarcomeric actinin), vascular phenotype (vascular endothelial growth factor, hepatocyte growth factor, von Willebrand factor), and smooth muscle differentiation (smooth muscle actin, calponin) were specific and spanning exons, and are reported in Table 1. To evaluate the quality of the product of real-time PCR assays, melting curve analysis was performed after each assay. Relative expression was determined using the delta-CT method with glyceraldehyde 3-phosphate dehydrogenase (GAPDH) as the reference gene.

\section{Immunostaining}

Cells were cultured for a period of 10 days with and without HA + BU + RA. After 10 days, the cells were treated with trypsin, and the resulting suspension was cultured at low density to allow visualization of individual cells. The cultures were fixed with $4 \%$ paraformaldehyde. Cells were exposed overnight at $4{ }^{\circ} \mathrm{C}$ to mouse monoclonal antibodies against $\alpha$-sarcomeric actinin, cardiac troponin T, von Willebrand factor, or vascular endothelial growth factor, smooth muscle actin, and calponin (Thermo Scientific) or with rabbit

Table I Description of primers used in real-time polymerase chain reaction

\begin{tabular}{|c|c|c|}
\hline Gene & Forward primer & Reverse primer \\
\hline GATA-4 & TGGCCTGTCATCTCACTACG & TAGCCTTGTGGGGAGAGCTT \\
\hline $\mathrm{Nkx}-2.5$ & CAAGTGTGCGTCTGCCTTT & GCGCACAGCTCTTTCTTTTC \\
\hline Prodynorphin & TGGCCAAGCTCTCTGGGTCA & TCATGGCCCATGCTATCCCC \\
\hline cTNT & CATGGAGAAGGACCTGAATGA & CGTCTCTCGATCCTGTCTTTG \\
\hline$\alpha-M H C$ & CCACCCAAGTTCGACAAGAT & CACAGAAGAGGCCCGAGTAG \\
\hline$\alpha$-sarcomeric actinin & CGAGCGCCATGAACCAGATA & GTGGAACCGCATTTTTCCCC \\
\hline Tbx5 & CAGAGTCGGCACAGCGGCAA & GTGGGGAGCCATGGTTGGCC \\
\hline Mef2C & GCCCTGAGTCTGAGGACAAG & AGTGAGCTGACAGGGTTGCT \\
\hline VEGF & AGAAGGAGGAGGGCAGAATC & ACACAGGATGGCTTGAAGATG \\
\hline HGF & ATTTGGCCATGAATTTGACCT & ACTCCAGGGCTGACATTTGAT \\
\hline vWF & CAACACCTGCATTTGCCGAA & ATGCGGAGGTCACCTTTCAG \\
\hline GAPDH & CAGCCTCAAGATCATCAGCA & TGTGGTCATGAGTCCTTCCA \\
\hline Sox2 & CACATGAACGGCTGGAGCA & TGCTGCGAGTAGGACATGCTG \\
\hline OCT4 & CTCACCCTGGGGGTTCTAT & CTCCAGGTTGCCTCTCACTC \\
\hline Nanog & CATGAGTGTGGATCCAGCT & CCTGAATAAGCAGATCCAT \\
\hline Smooth muscle actin & GACCTTTGGCTTGGCTTGTC & AGCTGCTTCACAGGATTCCC \\
\hline Calponin & CAGCATGGCGAAGACGAAAG & GAGGATGCCATGCAGGGAG \\
\hline
\end{tabular}

Abbreviations: cTNT, cardiac troponin T; vWF, von Willebrand factor; GAPDH, glyceraldehyde 3-phosphate dehydrogenase; VEGF, vascular endothelial growth factor; HGF, hepatocyte growth factor; MHC, myosin heavy chain; Tbx5, T-box 5; Mef2C, Myocyte Enhancer Factor 2C; Sox2, SRY (sex determining region Y)-box 2; OCT4, octamer-binding transcription factor 4. 
polyclonal antibodies against $\alpha$-myosin heavy chain (Santa Cruz Biotechnology, Inc.), and stained at $37^{\circ} \mathrm{C}$ for one hour with fluorescein-conjugated goat IgG. All microscopy analysis was performed with a confocal microscope (TCSSP5, Leica, Nussloch, Germany). DNA was visualized with $1 \mu \mathrm{g} /$ $\mathrm{mL}$ 4',6-diamidino-2-phenylindole (DAPI).

\section{Immunoblotting analysis}

Cells were cultured in the presence or absence of $\mathrm{HA}+\mathrm{BU}+\mathrm{RA}$ for 24,48 , or 72 hours and for 7 or 10 days. Total cell lysates from hAFSCs were electrophoresed on 10\% Novex Tris-glycine polyacrylamide gels (Invitrogen) in MOPS sodium dodecyl sulfate running buffer using an XCell SureLock ${ }^{\mathrm{TM}}$ Mini-Cell (Invitrogen) according to the instructions provided by the manufacturer. After protein transfer to polyvinylidene difluoride membranes (Invitrogen), and membrane saturation and washing, immunoreaction was carried out for one hour at room temperature in the presence of the primary antibody, antisera against GATA-4 (Santa Cruz Biotechnology, Inc.), Nkx-2.5 (Santa Cruz), Tbx5 (Thermo Scientific), Mef2C (Thermo Scientific), $\alpha$-sarcomeric actinin (Sigma-Aldrich), $\alpha$-myosin heavy chain (Santa Cruz Biotechnology, Inc.), cardiac troponin T (Thermo Scientific), vascular endothelial growth factor (Thermo Scientific), hepatocyte growth factor (Thermo Scientific), von Willebrand Factor (Santa Cruz Biotechnology, Inc.), smooth muscle actin (Thermo Scientific), calponin (Thermo Scientific), Oct4 (Santa Cruz Biotechnology, Inc.), Sox2 (Sigma-Aldrich), Nanog (Santa Cruz Biotechnology, Inc.), and GAPDH (Santa Cruz Biotechnology, Inc.) diluted to 1:1000. After additional washing, membranes were incubated with antirabbit (Nkx2.5, Tbx5, Mef2C, myosin heavy chain, vascular endothelial growth factor, Oct4, Sox2, Nanog, GAPDH) or antimouse (GATA4, cardiac troponin T, $\alpha$-sarcomeric actinin, hepatocyte growth factor, von Willebrand factor, smooth muscle actin, calponin), and horseradish peroxidase-conjugated secondary antibody (Pierce Biotechnology, Rockford, IL, USA). Targeted protein expression was assessed using a chemoluminescence detection system (ECL Western blotting detection reagents were from Amersham Biosciences Corporation, Piscataway, NJ, USA).

\section{Ultrastructural analysis of $\mathrm{HA}+\mathrm{BU}+\mathrm{RA}$-treated cells}

Ultrastructural features of the cultured cells were determined using transmission (TEM) and scanning electron (SEM) microscopy. Cells cultured in the absence and presence of $\mathrm{HA}+\mathrm{BU}+\mathrm{RA}$ for 10 days were washed with phosphate-buffered saline and then fixed in $0.1 \mathrm{M} \mathrm{pH} \mathrm{7.4}$ phosphate-buffered saline containing $2.5 \%$ glutaraldehyde for 2 hours and post-fixed in osmium tetroxide. For TEM study, the specimens were embedded in Durcupan ${ }^{\text {TM }}$ ACM (Sigma), ultrathin sections were collected in copper grids, stained with uranyl acetate and lead citrate, and then observed and photographed using a 902A electron microscope (Zeiss, Oberkochen, Germany). For SEM, the cells were dehydrated with acetone, followed by hexamethyldisilazane, then coated with gold and observed by SEM (Inspect S and Quanta 200, FEI Quanta, Eindhoven, The Netherlands).

\section{Data analysis}

The statistical data analysis was performed using Statistical Package for the Social Sciences version 13 software (SPSS Inc, Chicago, IL, USA). For this study, nonparametric statistical tests were used, ie, the Kruskal-Wallis rank sum and Wilcoxon signed-rank test. The former was used to evaluate the distributions and homogeneity of each group variance at different times of observation; the latter was used to evaluate, in the same group, differences (delta-CT) between the data collected over a period of observation and the reference value at baseline. All results were considered to be statistically significant at $P<0.05$.

\section{Results \\ Culturing hAFSCs with a mixture of $\mathrm{HA}, \mathrm{BU}$, and RA enhances expression of cardiogenic and angiogenic genes}

Figure 1 shows that all cells used in this study stained positive for CD90, CD105, CD44, CD29, Oct4, Sox2, and Nanog, and negative for CD34, CD133, and CD45 before $\mathrm{HA}+\mathrm{BU}+\mathrm{RA}$ treatment. In hAFSCs, a mixture of $\mathrm{HA}+\mathrm{BU}+\mathrm{RA}$ significantly increased (mean \pm standard error of the mean; $\mathrm{n}=6 ; P<0.05)$ the expression of GATA-4 and Nkx-2.5, encoding a zinc finger and a homeodomain essential for cardiogenesis. ${ }^{13,14}$ As shown by real-time PCR analysis (Figure 2), the transcriptional effect of $\mathrm{HA}+\mathrm{BU}+\mathrm{RA}$ on these genes was evident just 24 hours after exposure. Similarly, even expression of the prodynorphin gene, a known orchestrator of cardiogenesis, ${ }^{15-17}$ and of Tbx 5 and Mef2C, both having an essential role in the cardiac commitment, was significantly enhanced $(P<0.05)$ in HA + BU + RA-treated cells. The cardiacspecific genes for $\alpha$-sarcomeric actinin, $\alpha$-myosin heavy 


\begin{tabular}{|c|c|c|}
\hline \multirow{4}{*}{ Stemness markers } & Oct-4 & $95.9 \% \pm 2.1 \%$ \\
\cline { 2 - 3 } & Sox-2 & $96.4 \% \pm 0.8 \%$ \\
\cline { 2 - 3 } & Nanog & $96.2 \% \pm 2.8 \%$ \\
\hline \multirow{4}{*}{ MSC markers } & CD44 & $96.8 \% \pm 3.1 \%$ \\
\cline { 2 - 3 } & CD29 & $97.8 \% \pm 1.8 \%$ \\
\cline { 2 - 3 } & C105 & $96 \% \pm 3.2 \%$ \\
\cline { 2 - 3 } & CD90 & $94.1 \pm 3.1$ \\
\hline \multirow{5}{*}{ Hemopoietic markers } & CD45 & 0 \\
\cline { 2 - 3 } & CD133 & 0 \\
\cline { 2 - 3 } & CD34 & 0 \\
\hline
\end{tabular}

Figure I Flow cytometric immunophenotype analysis of stem cells derived from primitive fetal cells present in human amniotic fluid (hAFSCs). Undifferentiated hAFSCs were stained with primary antibodies specific for stemness markers (Oct4 Sox2, Nanog), MSC markers (CD44, CD29, CD I05, CD90), or hemopoietic markers (CD45, CDI33, CD34) and with fluorescein isothiocyanate-conjugated secondary antibody. The graphics show the immunophenotype analysis (mean \pm standard error of the mean; $\mathrm{n}=6 ; P<0.05$ ).

Abbreviation: MSC, mesenchymal stem cells.

chain, and cardiac troponin $\mathrm{T}$ showed the same trend (Figure 2). Figure 2 shows also that the expression of a set of vasculogenic genes, including for vascular endothelial growth factor, hepatocyte growth factor, and von Willebrand factor (Figure 1D-F), was markedly increased (mean \pm standard error of the mean; $\mathrm{n}=6 ; P<0.05$ ) in cells exposed to $\mathrm{HA}+\mathrm{BU}+\mathrm{RA}$, even after 10 days of treatment. These genes have been shown to play a pivotal role in both endothelial tissue formation and neoangiogenesis. ${ }^{18,19}$ Moreover, in cells treated with $\mathrm{HA}+\mathrm{BU}+\mathrm{RA}$, expression of smooth muscle actin and calponin, two smooth muscle-related genes, was superimposable on what was detected in untreated control cells (Figure 2).

\section{Exposure of hAFSCs to a mixture of $\mathrm{HA}, \mathrm{BU}$, and RA downregulates expression of stemness marker genes}

Figure 3 shows that treatment with $\mathrm{HA}+\mathrm{BU}+\mathrm{RA}$ influenced the expression of Nanog, Sox2, and the octamer binding protein, Oct4; all of these genes code for specific factors controlling self-renewal and differentiation of stem cells. ${ }^{20}$ As expected, during commitment toward a differentiated phenotype, Nanog, Sox2, and Oct4 were downregulated (mean \pm standard error of the mean; $\mathrm{n}=6 ; P<0.05$ ) in cells exposed to $\mathrm{HA}+\mathrm{BU}+\mathrm{RA}$ (Figure 3). This effect was evident after 24 hours, and was still clear after 10 days in culture.

\section{Exposure of hAFSCs to a mixture of $\mathrm{HA}, \mathrm{BU}$, and RA modulates expression of cardiac, vascular, and stemness-related proteins}

Figure 4 shows the effect of treatment with $\mathrm{HA}+\mathrm{BU}+\mathrm{RA}$ on the expression of cardiac and vascular-restricted marker proteins. Western blot analysis revealed that GATA-4, Nkx-2.5, Mef2C, Tbx5, $\alpha$-sarcomeric actinin, and $\alpha$-myosin heavy chain, representative of cardiac specification, and vascular endothelial growth factor, hepatocyte growth factor, and von Willebrand factor, representative of vascular specification, were significantly more expressed $(P<0.05)$ in hAFSCs cultured in the presence of $\mathrm{HA}+\mathrm{BU}+\mathrm{RA}$ than in untreated control cells (Figure 4). Such an increase was evident after 2 days of treatment and persisted during the following 8 days in culture (Figure 4). On the other hand, no significant expression was detected for smooth muscle actin and calponin, two specific markers of smooth muscle lineage (Figure 4). In hAFSCs exposed to HA + BU + RA, expression of Sox2, Nanog, and Oct4 proteins mirrored the transcriptional responses elicited by the mixture of these compounds; in fact all of these proteins were expressed with lower levels in treated as compared with untreated cells.

\section{hAFSCs treated with a mixture of HA, $B U$, and RA exhibit a high differentiation rate toward cardiogenic and vascular phenotypes}

The overexpression of cardiovascular-restricted marker proteins in HA + BU + RA-treated cells was also confirmed by confocal microscopy analysis. The cardiac specific markers $\alpha$-sarcomeric actinin, the myosin heavy chain, and the vascular specific marker, von Willebrand factor, were expressed in a limited number $(1 \%-5 \%)$ of untreated hAFSCs (Figure 4). Interestingly, treatment with $\mathrm{HA}+\mathrm{BU}+\mathrm{RA}$ markedly increased the yield of cells expressing both cardiac and vascular marker proteins (Figure 5). In this regard, we have previously described ${ }^{11,21}$ that adipose-derived mesenchymal stem cells spontaneously express vasculogenic markers (vascular endothelial growth factor, hepatocyte growth factor). Moreover, Figure 5 shows that smooth muscle actin and calponin, specific for smooth muscle differentiation, are not influenced by $\mathrm{HA}+\mathrm{BU}+\mathrm{RA}$ treatment. 


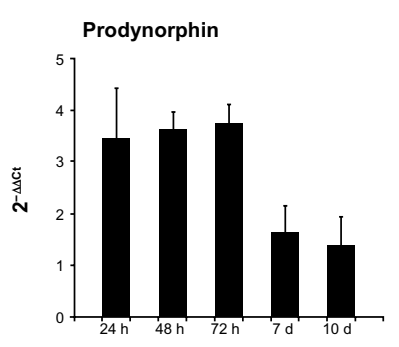

Nkx-2.5
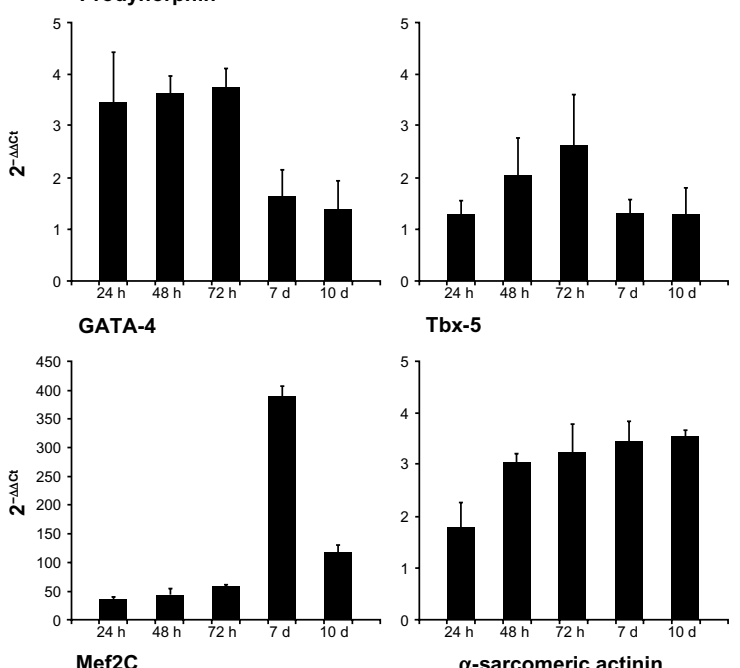

Tbx-5
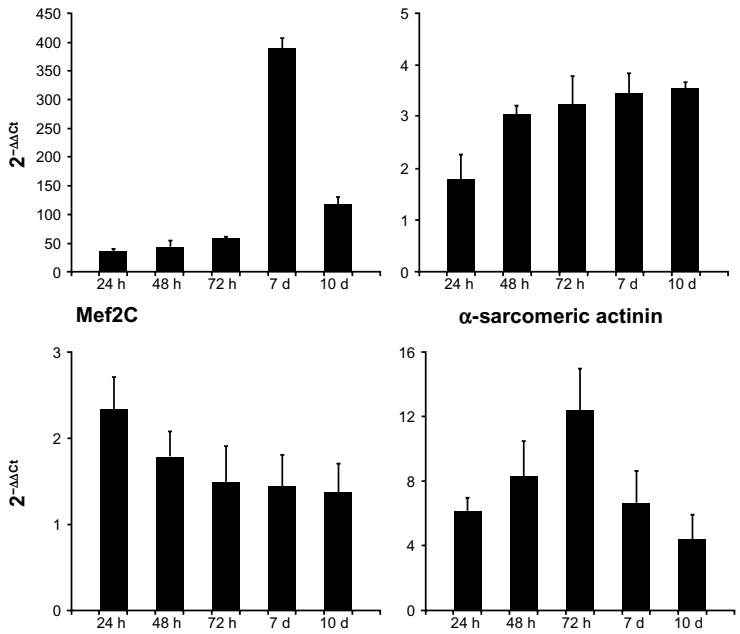

$\alpha$-myosin heavy chain
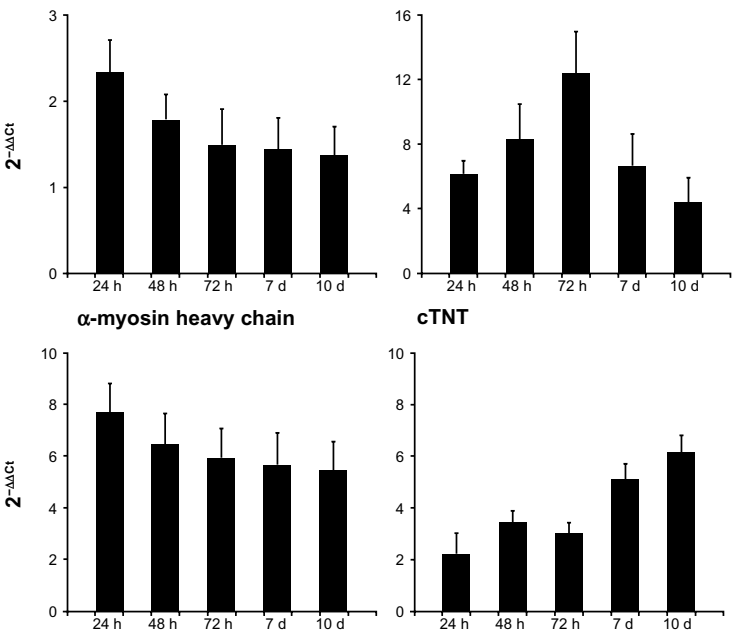

$$
\text { cTNT }
$$

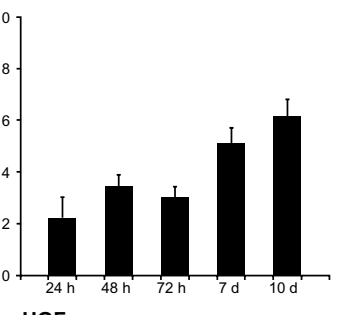

VEGF

HGF

\section{vWF}
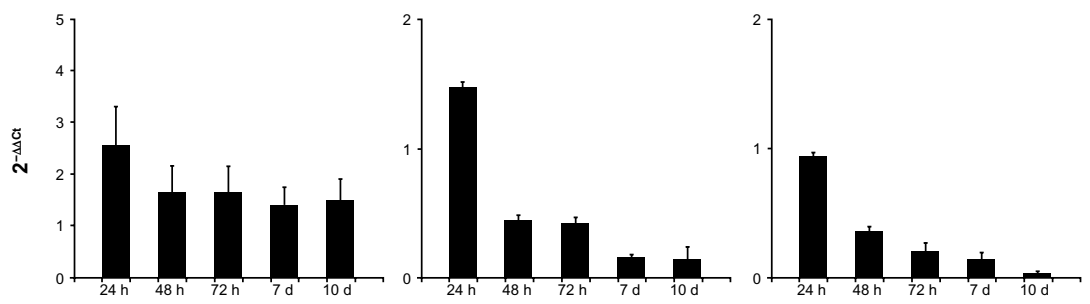

Smooth muscle actinin

Calponin

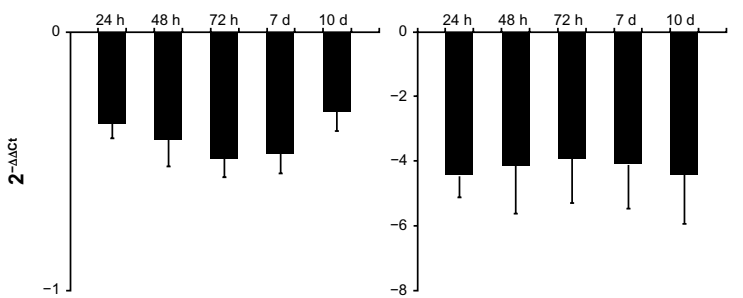

Figure 2 Effect of $\mathrm{HA}+\mathrm{BU}+\mathrm{RA}$ on expression of genes specific for cardiogenic, angiogenic, and smooth muscle in stem cells derived from primitive fetal cells present in human amniotic fluid. Cells were exposed for I, 2, 3, 7, and I 0 days in the absence or presence of HA $2 \mathrm{mg} / \mathrm{mL}+\mathrm{BU} 5 \mathrm{mM}+\mathrm{RA} I \mu M$. The mRNA amounts of prodynorphin, Nkx-2.5, GATA-4, Tbx-5, Mef2C, $\alpha$-sarcomeric actinin, $\alpha$-myosin heavy chain, cTNT, VEGF, HGF, vWF, smooth muscle actin, and calponin from HA + BU + RA-treated or untreated cells were normalized to GAPDH, and the mRNA expression levels in HA + BU + RA-treated cells was plotted at each time point as fold change relative to expression in untreated control cells, defined as I. All the HA + BU + RA-treated cells at each time point were significantly different from untreated control cells (mean \pm standard error of the mean; $\mathrm{n}=6 ; \mathrm{P}<0.05$ ).

Abbreviations: HA, hyaluronic acid; BU, butyric acid; RA, retinoic acid; cTNT, cardiac troponin T; vWF, von Willebrand factor; VEGF, vascular endothelial growth factor; HGF, hepatocyte growth factor; mRNA, messenger RNA; GAPDH, glyceraldehyde 3-phosphate dehydrogenase. 

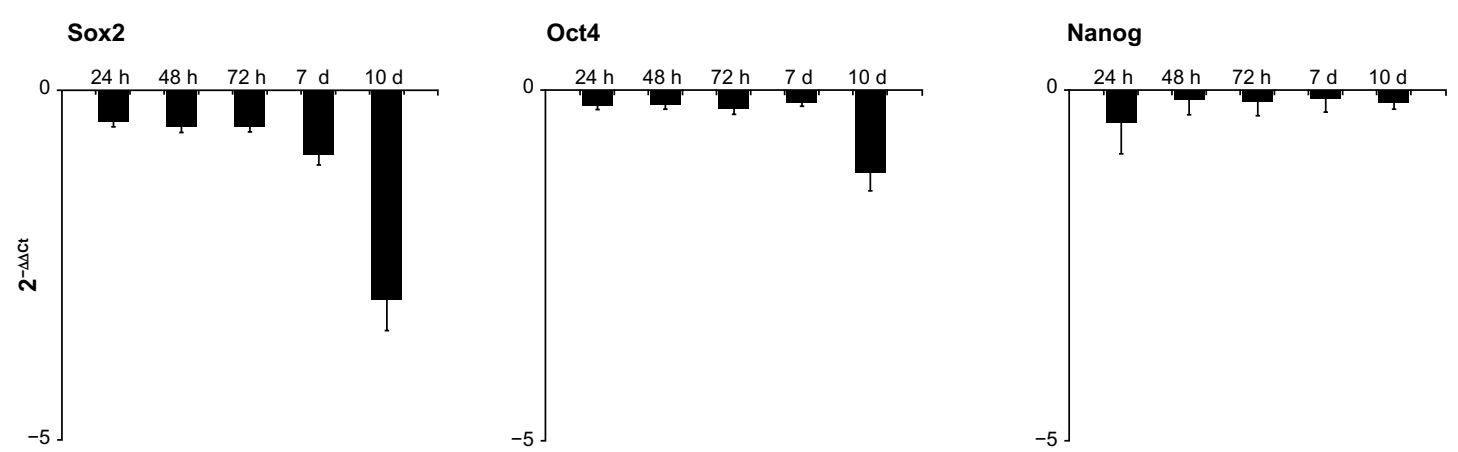

Figure 3 Effects on stem cells derived from primitive fetal cells present in human amniotic fluid (hAFSCs) of exposure to a mixture of HA + BU + RA on pluripotency gene transcription. hAFSCs were exposed for I, 2, 3, 7, or 10 days in the absence or presence of HA $2 \mathrm{mg} / \mathrm{mL}+\mathrm{BU} 5 \mathrm{mM}+\mathrm{RA}$ I $\mu$ M. The mRNA amounts of Sox2, Oct4, and Nanog from HA + BU + RA-treated or untreated cells were normalized to GAPDH, and the mRNA expression levels in HA + BU + RA-treated cells were plotted at each time point as fold change relative to expression in untreated control cells, defined as I. All the HA + BU + RA-treated cells at each time point were significantly different from untreated control cells (mean \pm standard error of the mean; $n=6 ; P<0.05$ ).

Abbreviations: HA, hyaluronic acid; BU, butyric acid; RA, retinoic acid; GAPDH, glyceraldehyde 3-phosphate dehydrogenase; mRNA, messenger RNA.

$-(\mathrm{HA}+\mathrm{BU}+\mathrm{RA})$

GATA4

Nkx-2.5

Tbx-5

Mef2C

Actinin

$\mathrm{MHC}$

cTNT

VEGF

HGF

vWF

SMA
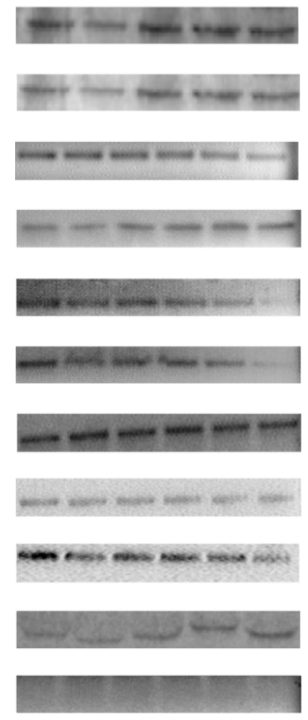

Calponin

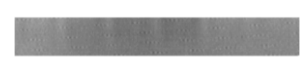

Sox2

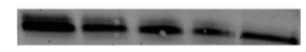

Oct4

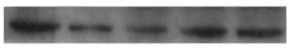

Nanog

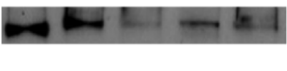

GAPDH
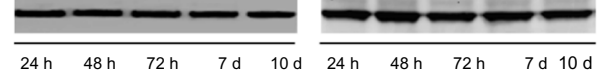

Figure 4 Exposure of stem cells derived from primitive fetal cells present in human amniotic fluid (hAFSCs) to HA + BU + RA modulates expression of selected, tissuerestricted, and stemness-related proteins. Total lysates were isolated from hAFSCs cultured for different periods of time, ie, 24, 48, and 72 hours, and 7 and 10 days, in the absence $[-(\mathrm{HA}+\mathrm{BU}+\mathrm{RA})]$ or presence $[+(\mathrm{HA}+\mathrm{BU}+\mathrm{RA})]$ of $\mathrm{HA} 2 \mathrm{mg} /$ $\mathrm{mL}+\mathrm{BU} 5 \mathrm{mM}+\mathrm{RA} I \mu \mathrm{M}$. Samples were analyzed by Western blot, using polyclonal antisera against GATA4, Nkx-2.5, Tbx-5, Mef2C, $\alpha$-sarcomeric actinin, MHC, cTNT, VEGF, HGF, vWF, SMA, calponin, Sox2, Oct4, and Nanog and GAPDH. The sizes of the bands were determined using prestained marker proteins. The data presented are representative of five separate experiments.

Abbreviations: HA, hyaluronic acid; BU, butyric acid; RA, retinoic acid; cTNT, cardiac troponin T; vWF, von Willebrand factor; VEGF, vascular endothelial growth factor; HGF, hepatocyte growth factor; MHC, $\alpha$-myosin heavy chain; SMA, smooth muscle actin; GAPDH, glyceraldehyde 3-phosphate dehydrogenase.

\section{Mixture of HA, BU, and RA shows} a higher differentiation capability toward cardiogenic and vascular phenotypes as compared with $\mathrm{HA}, \mathrm{BU}$, and RA alone

To evaluate the effect of HA, BU, and RA on cardiovascular differentiation, hAFSCs were exposed to a mixture of $\mathrm{HA}+\mathrm{BU}+\mathrm{RA}, \mathrm{HA}+\mathrm{BU}, \mathrm{HA}+\mathrm{RA}$, or RA + BU, for 10 days. Using flow cytometric analysis, we then evaluated the expression of $\alpha$-sarcomeric actinin, $\alpha$-myosin heavy chain, and von Willebrand factor. Figure 6 shows that the mixture containing $\mathrm{HA}+\mathrm{BU}+\mathrm{RA}$ was significantly $(P<0.05)$ more effective in inducing the appearance of the cardiac and vascular phenotype as compared with the mixtures containing only two compounds $(\mathrm{HA}+\mathrm{BU}, \mathrm{HA}+\mathrm{RA}$, $\mathrm{BU}+\mathrm{RA})$.

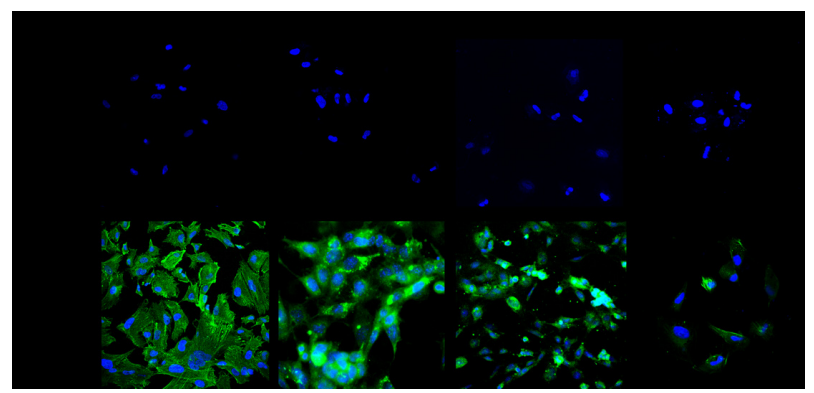

Figure $5 \mathrm{HA}+\mathrm{BU}+\mathrm{RA}$ treatment mediated differentiation of stem cells derived from primitive fetal cells present in human amniotic fluid. Expression of $\alpha$-sarcomeric actinin, $\alpha$-myosin heavy chain, cardiac troponin T, von Willebrand factor, and vascular endothelial growth factor was assessed in cells cultured in the absence $[-(\mathrm{HA}+\mathrm{BU}+\mathrm{RA})]$ or presence $[+(\mathrm{HA}+\mathrm{BU}+\mathrm{RA})]$ of $\mathrm{HA} 2 \mathrm{mg} / \mathrm{mL}+$ BU $5 \mathrm{mM}+\mathrm{RA} I \mu \mathrm{M}$ for 10 days, and cultured for an additional one day in tissue chamber slides suitable for immunofluorescence staining. Images were obtained using a confocal microscope (TCSSP5, Leica, Nussloch, Germany) using a 20× objective. Nuclei are labeled with 4',6-diamidino-2-phenylindole (DAPI, blue). Data shown are representative of five separate experiments.

Abbreviations: HA, hyaluronic acid; $\mathrm{BU}$, butyric acid; RA, retinoic acid. 


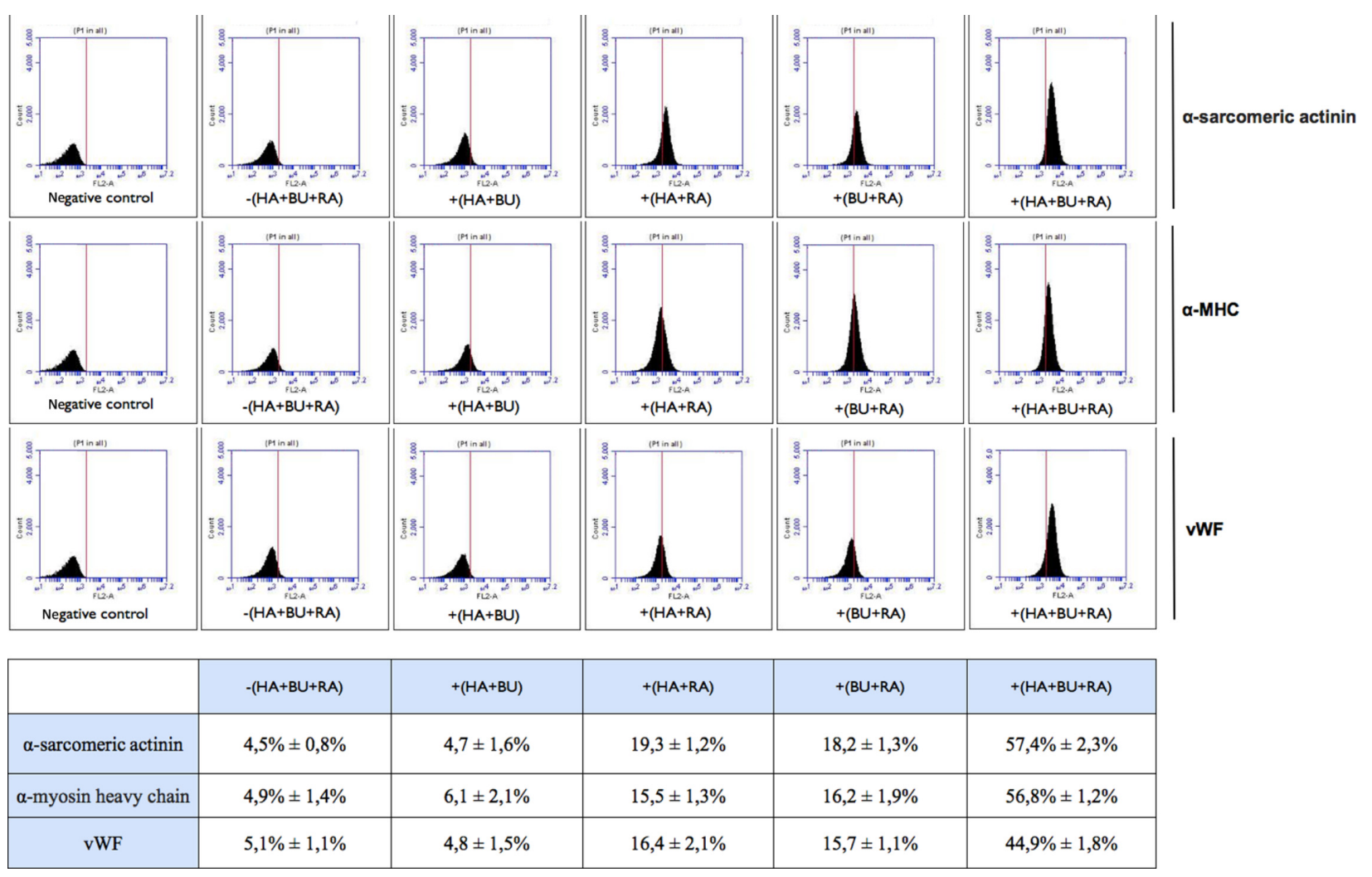

Figure 6 Flow cytometry analysis of cell lineage marker expression in stem cells derived from primitive fetal cells present in human amniotic fluid (hAFSCs). The hAFSCs were cultured in the absence $[-(\mathrm{HA}+\mathrm{BU}+\mathrm{RA})]$ or presence $[+(\mathrm{HA}+\mathrm{BU}+\mathrm{RA})]$ of HA $2 \mathrm{mg} / \mathrm{mL}+\mathrm{BU} 5 \mathrm{mM}+\mathrm{RA} I \mu M$ for 10 days. Cells were stained with primary antibodies specific for the marker of interest, in particular, $\alpha$-sarcomeric actinin, $\alpha-M H C$, and $v W F$, and with fluorescein isothiocyanate-conjugated secondary antibody. In order to validate the results, negative control samples, devoid of the antibody of interest, were used to set the basal fluorescence. The graphics show an increase in fluorescence and in the percentage of positively stained elements, corresponding to differentiated cells, as compared with untreated cells [-(HA + BU + RA $)]$. The data shown are representative of six individual experiments.

Abbreviations: HA, hyaluronic acid; BU, butyric acid; RA, retinoic acid; vWF, von Willebrand factor; $\alpha-M H C, \alpha$-myosin heavy chain.

\section{Assessment of morphologic} modifications induced by $\mathrm{HA}+\mathrm{BU}+\mathrm{RA}$ during hAFSC differentiation towards the cardiovascular phenotype

Cardiac lineage commitment was further inferred from the observation that $\mathrm{HA}+\mathrm{BU}+\mathrm{RA}$ exposure was associated with a typical myofibrillar organization, as highlighted by electron microscopy analysis (Figure 7). In untreated cells, the nucleus, located in the cell periphery, showed an indented aspect (Figure 7A, thin arrow), with small areas of heterochromatin and a nucleolus (thick arrow) very evident. The cytoplasm appeared homogeneous with few organelles. TEM observation at higher magnification of the untreated cell cytoplasm showed poor presence of organelles; in particular, there were only some cisterns of the rough endoplasmic reticulum (Figure 7C, arrow). In HA + BU + RA-treated cells, the cytoplasm appeared to be full of organelles, in particular mitochondria. The nucleus had an irregular shape with numerous indents (Figure 7B, thin arrow), and heterochromatin near the membrane and nucleolus (thick arrow) was very visible. Treated cells observed with higher magnification TEM revealed the rich presence of organelles, ie, numerous mitochondria with lamellar crests (Figure 7B, thin arrow), and vacuoles (Figure 7B, asterisk).

Exclusively, in cells treated with $\mathrm{HA}+\mathrm{BU}+\mathrm{RA}$, numerous intracytoplasmic fibers were evident (Figure 7D, thick arrow), with an initial organization in bundles, extending parallel, although typical sarcomeric organization was not yet evident. In HA + BU + RA-treated cells, many mitochondria with large lamellar ridges were also present, unlike control cells, in which these organelles were less abundant and showed thinner ridges. Even the rough endoplasmic reticulum appeared more abundant in treated cells, as well as the number of intracytoplasmic vesicles.

Both cells had a nucleus with irregular morphology, with numerous indentations in dispersed chromatin and a nucleolus always evident. On SEM, a different morphology of the plasma membrane could be seen: it appeared substantially smooth or with little and short microvilli in control cells (Figure 7E, 7G, asterisk) on the other hand, the surface 


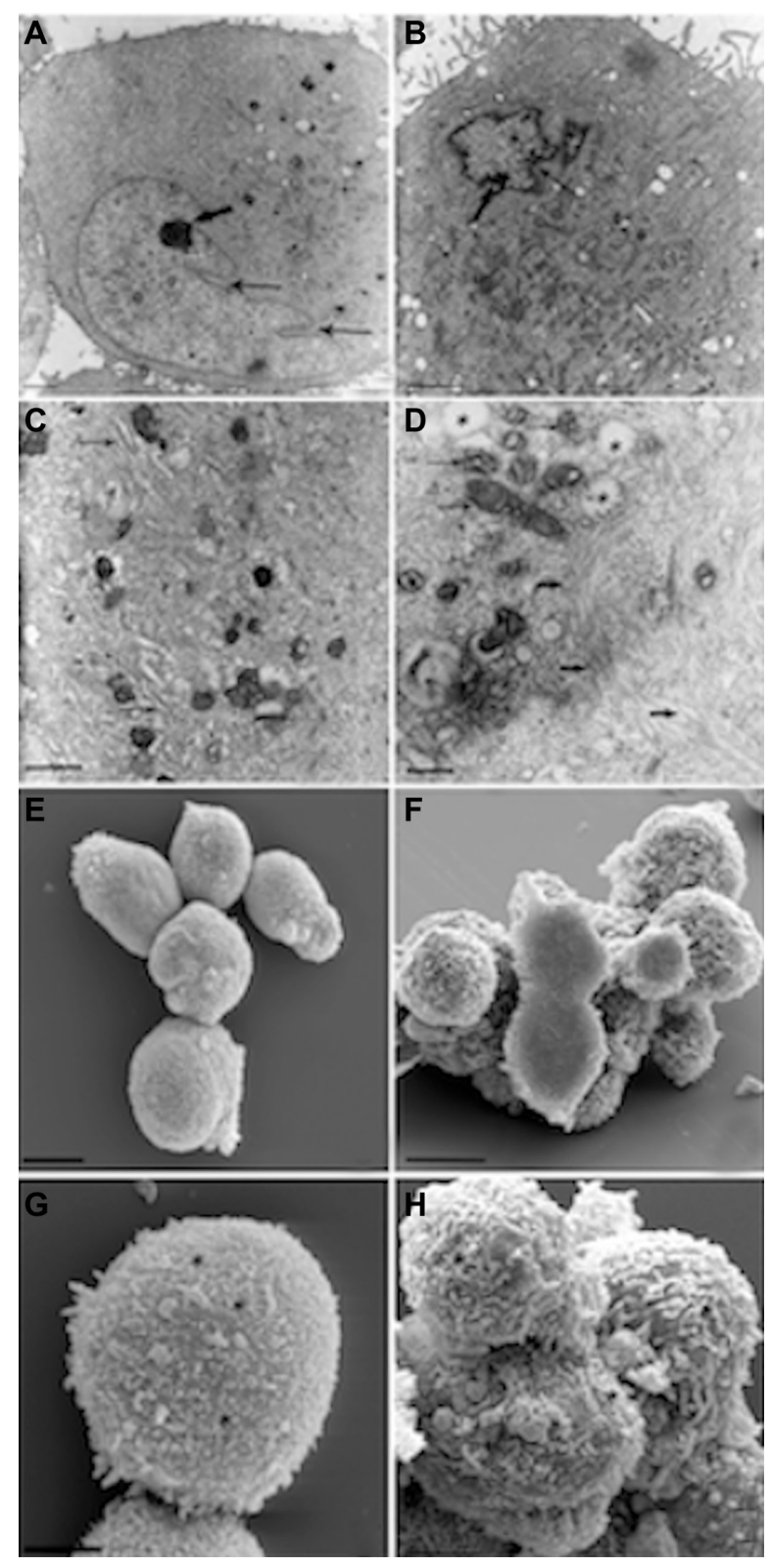

Figure 7 Morphologic analysis of stem cells derived from primitive fetal cells present in human amniotic fluid (hAFSCs) during $\mathrm{HA}+\mathrm{BU}+\mathrm{RA}$-induced differentiation toward the cardiovascular phenotype. hAFSCs were cultured in the absence (A, C, $\mathbf{E}$ and $\mathbf{G}$ ) or presence (B, D, F and $\mathbf{H}$ ) of HA $2 \mathrm{mg} / \mathrm{mL}+\mathrm{BU} 5 \mathrm{mM}+\mathrm{RA} I \mu \mathrm{M}$ for 10 days. TEM analysis (A-D) or SEM analysis (E-H). (A) TEM imaging of untreated cells, 3,000×, scale bar $5 \mu \mathrm{m}$; (B) TEM imaging of HA + BU + RA-treated cells, $4,400 \times$, scale bar $5 \mu \mathrm{m}$; (C) TEM imaging of untreated cells, 7,000×, scale bar $5 \mu \mathrm{m}$; (D) TEM imaging of treated cells, 12,000×, scale bar I $\mu \mathrm{m}$; (E) SEM imaging of untreated cells, I,600×, scale bar $10 \mu \mathrm{m}$; (F) SEM imaging of treated cells, 4,500×, scale bar $10 \mu \mathrm{m}$; (G) SEM imaging of untreated cells, 2,400×, scale bar $5 \mu \mathrm{m}$; (H) SEM imaging of treated cells, $8,000 \times$, scale bar $5 \mu \mathrm{m}$. See text for more details.

Abbreviations: HA, hyaluronic acid; BU, butyric acid; RA, retinoic acid; SEM, scanning electron microscopy; TEM, transmission electron microscopy.

area of the $\mathrm{HA}+\mathrm{BU}+\mathrm{RA}$-treated cells, taken at a higher magnification SEM, showed a large presence of microvilli (Figure 7H, asterisk), with different thicknesses and lengths, which almost completely covered the cell membrane. The presence of abundant rough endoplasmic reticulum vesicles and microvilli could be related to the synthetic activity and paracrine secretion of cells committed toward the cardiovascular phenotype.

\section{Discussion}

The present study highlights the fact that hAFSCs are committed toward cardiac and angiogenic phenotypes after exposure to a mixture of HA, BU, and RA. We observed that the percentage of cells positively stained for the cardiac phenotype marker, alpha-sarcomeric actinin, was higher when hAFSCs were treated with HA + BU + RA. In these cells, the appearance of this cardiac lineage-specific protein was preceded by a significant increase in expression of the cardiogenic genes GATA-4 and Nkx-2.5 and their corresponding proteins, and expression of the prodynorphin gene, a well known orchestrator of cardiogenesis. ${ }^{16,17}$ The appearance of a cardiac phenotype was further inferred by electron microscopy analysis, which clearly revealed an initial stage of sarcomeric organization in $\mathrm{HA}+\mathrm{BU}+\mathrm{RA}-$ treated cells.

In this study, we have highlighted consistent expression of the two vasculogenic genes, vascular endothelial growth factor and hepatocyte growth factor, in HA + BU + RAtreated cells; in particular, von Willebrand factor was upregulated in these hAFSCs, when compared with untreated control cells, as assessed by real-time PCR and Western blotting. Further, confocal microscopy and flow cytometry analysis confirmed the vascular commitment of hAFSCs by revealing a significant increase in von Willebrand factor-positive elements when hAFSCs were exposed to HA + BU + RA. As expected, cells committed toward the cardiac and vascular phenotypes showed downregulation of expression of the pluripotency regulators Nanog, Sox2, and Oct, both at the transcriptional and protein levels. These findings further confirmed a commitment of hAFSCs toward specific cellular phenotypes. Vascular differentiation of human mesenchymal stem cells is very important for tissue transplantation in regenerative medicine, because it represents a source which is working rapidly for tissue regeneration. Preclinical and clinical studies reported that the improvement in cardiac function and tissue regeneration observed after mesenchymal stem cell transplantation seems to depend on the release of paracrine factors.

Human mesenchymal stem cells have been found to express vascular endothelial growth factor, hepatocyte growth factor, and other arteriogenic cytokines promoting vasculogenesis through paracrine mechanisms in vitro and in vivo. ${ }^{22-25}$ In addition, undifferentiated hAFSCs have been 
used in the recovery of neurogenic and cardiac function in ischemic mouse and rat stroke models. ${ }^{26,27}$

However, despite these features, the cardiovascular commitment of human mesenchymal stem cells is an extremely low-yield process and the differentiated elements have a poor chance of survival. Other authors have described differentiation of hAFSCs toward vascular phenotypes with a higher yield, using media containing a mixture of specific growth factors and shear force stimuli. ${ }^{28}$ Indeed, genetically modified mesenchymal stem cells have been shown to have a higher regenerative potential than nonengineered cells. In particular, some authors have demonstrated viability and engraftment from cells overexpressing secretable factors with cardioprotective properties. ${ }^{29-33}$

An alternative approach to improve paracrine release of angiogenic factors such as vascular endothelial growth factor and hepatocyte growth factor has been to precondition human mesenchymal stem cells of the fetal membrane (FMhMSCs), bone marrow, and dental pulp with HBR, which elicits a remarkable increase in cell survival and differentiation. ${ }^{10}$ To this end, transplantation of FMhMSCs preconditioned ex vivo into infarcted rat myocardium with HBR primed a normalization of myocardial performance and a significant decrease of scar tissue through paracrine mechanisms. Of note, even mesenchymal stem cells obtained from other sources, such as human adipose-derived stem cells pretreated with $\mathrm{HA}+\mathrm{BU}+\mathrm{RA}$ favored survival of islet transplantation in streptozotocin-diabetic rats. ${ }^{11}$

In the present work, we observed that $\mathrm{HA}+\mathrm{BU}+\mathrm{RA}-$ treated hAFSCs have a higher yield of cardiovascular differentiation, as compared with $\mathrm{HA}+\mathrm{BU}+\mathrm{RA}$-treated FMhMSCs differentiated toward the same lineages (unpublished data). The possibility that hAFSCs may represent a suitable source of potentially transplantable cells in large-scale allogenic settings is supported by a number of interrelated observations, including their easy isolation and growth, affordability of expansion even as clonal growth, ability to differentiate into all germ layers, ${ }^{12,34-36}$ lack of immunogenicity due to low expression of the major histocompatibility complex class II antigen, ${ }^{37}$ and the absence of signs of tumorigenicity in vitro and in vivo. ${ }^{38,39}$ On the other hand, a limitation to the therapeutic application of these cells lies in the fact that they can only be obtained from pregnant women.

We have previously shown that the effect of a mixed ester of HBR on cardiac differentiation in murine embryonic and human mesenchymal stem cells obtained from fetal membranes was related to increased expression of the cardiogenic transcription factor Nkx-2.5 through Smad4 binding to its own consensus Smad site (Maioli M et al Plos One 2010). ${ }^{40}$ On the basis of these crucial data, we hypothesize that a similar mechanism is involved even when hAFSCs are exposed to $\mathrm{HA}+\mathrm{BU}, \mathrm{HA}+\mathrm{RA}, \mathrm{BU}+\mathrm{RA}$, or HA + BU + RA. Future experiments are needed to confirm this hypothesis.

Considering the positive outcome obtained in this study, we hypothesize that exposing hAFSCs to a mixture of $\mathrm{HA}+\mathrm{BU}+\mathrm{RA}$ could pave the way for a large-scale cell therapy approach, even if in vivo studies are needed in order to define further the fate of committed stem cells.

\section{Disclosure}

The authors declare no conflicts of interest in this work.

\section{References}

1. Baksh D, Song L, Tuan RS. Adult mesenchymal stem cells: characterization, differentiation, and application in cell and gene therapy. J Cell Mol Med. 2004;8(3):301-316.

2. Pittenger MF, Martin BJ. Mesenchymal stem cells and their potential as cardiac therapeutics. Circ Res. 2004;95(1):9-20.

3. Zimmet JM, Hare JM. Emerging role for bone marrow derived mesenchymal stem cells in myocardial regenerative therapy. Basic Res Cardiol. 2005;100(6):471-481.

4. De Coppi P, Bartsch G Jr, Siddiqui MM, et al. Isolation of amniotic stem cell lines with potential for therapy. Nat Biotechnol. 2007;25(1): 100-106.

5. Sartore S, Lenzi M, Angelini A, et al. Amniotic mesenchymal cells autotransplanted in a porcine model of cardiac ischemia do not differentiate to cardiogenic phenotypes. Eur J Cardiothorac Surg. 2005;28(5): 677-684.

6. Iop L, Chiavegato A, Callegari A, et al. Different cardiovascular potential of adult- and fetal-type mesenchymal stem cells in a rat model of heart cryoinjury. Cell Transplant. 2008;17(6):679-694.

7. Guan X, Delo DM, Atala A, Soker S. In vitro cardiomyogenic potential of human amniotic fluid stem cells. JTissue Eng Regen Med. 2011;5(3): 220-228.

8. Bollini S, Pozzobon M, Nobles M, et al. In vitro and in vivo cardiomyogenic differentiation of amniotic fluid stem cells. Stem Cell Rev. 2011;7(2):364-380.

9. Ventura C, Maioli M, Asara Y, et al. Butyric and retinoic mixed ester of hyaluronan. A novel differentiating glycoconjugate affording a high throughput of cardiogenesis in embryonic stem cells. J Biol Chem. 2004;279(22):23574-23579.

10. Ventura C, Cantoni S, Bianchi F, et al. Hyaluronan mixed esters of butyric and retinoic acid drive cardiac and endothelial fate in term placenta human mesenchymal stem cells and enhance cardiac repair in infarcted rat hearts. J Biol Chem. 2007;282(19):14243-14252.

11. Cavallari G, Olivi E, Bianchi F, et al. Mesenchymal stem cells and islet cotransplantation in diabetic rats: improved islet graft revascularization and function by human adipose tissue-derived stem cells preconditioned with natural molecules. Cell Transplant. 2012;21(12):2771-2781.

12. Tsai MS, Hwang SM, Tsai YL, Cheng FC, Lee JL, Chang YJ. Clonal amniotic fluid-derived stem cells express characteristics of both mesenchymal and neural stem cells. Biol Reprod. 2006;74(3): 545-551.

13. Grepin C, Robitaille L, Antakly T, Nemer M. Inhibition of transcription factor GATA-4 expression blocks in vitro cardiac muscle differentiation. Mol Cell Biol. 1995;15(8):4095-4102.

14. Biben C, Palmer S, Elliott DA, Harvey RP. Homeobox genes and heart development. Cold Spring Harb Symp Quant Biol. 1997;62:395-403.

15. Ventura C, Zinellu E, Maninchedda E, Maioli M. Dynorphin B is an agonist of nuclear opioid receptors coupling nuclear protein kinase $\mathrm{C}$ activation to the transcription of cardiogenic genes in GTR1 embryonic stem cells. Circ Res. 2003;92(6):623-629. 
16. Ventura C, Zinellu E, Maninchedda E, Fadda M, Maioli M. Protein kinase $\mathrm{C}$ signaling transduces endorphin-primed cardiogenesis in GTR1 embryonic stem cells. Circ Res. 2003;92(6):617-622.

17. Ventura C, Maioli M. Opioid peptide gene expression primes cardiogenesis in embryonal pluripotent stem cells. Circ Res. 2000;87(3): 189-194.

18. Duda DG, Fukumura D, Jain RK. Role of eNOS in neovascularization: NO for endothelial progenitor cells. Trends Mol Med. 2004;10(4): 143-145.

19. He H, Venema VJ, Gu X, Venema RC, Marrero MB, Caldwell RB. Vascular endothelial growth factor signals endothelial cell production of nitric oxide and prostacyclin through flk-1/KDR activation of c-Src. J Biol Chem. 1999;274(35):25130-25135.

20. Kashyap V, Rezende NC, Scotland KB, et al. Regulation of stem cell pluripotency and differentiation involves a mutual regulatory circuit of the NANOG, OCT4, and SOX2 pluripotency transcription factors with polycomb repressive complexes and stem cell microRNAs. Stem Cells Dev. 2009;18(7):1093-1108.

21. Bianchi F, Maioli M, Leonardi E, et al. A new non-enzymatic method and device to obtain a fat tissue derivative highly enriched in pericytelike elements by mild mechanical forces from human lipoaspirates. Cell Transplant. October 8, 2012. [Epub ahead of print.]

22. Kim DH, Yoo KH, Choi KS, et al. Gene expression profile of cytokine and growth factor during differentiation of bone marrow-derived mesenchymal stem cell. Cytokine. 2005;31(2):119-126.

23. Mayer H, Bertram H, Lindenmaier W, Korff T, Weber H, Weich H. Vascular endothelial growth factor (VEGF-A) expression in human mesenchymal stem cells: autocrine and paracrine role on osteoblastic and endothelial differentiation. J Cell Biochem. 2005;95(4): 827-839.

24. Kinnaird T, Stabile E, Burnett MS, et al. Marrow-derived stromal cells express genes encoding a broad spectrum of arteriogenic cytokines and promote in vitro and in vivo arteriogenesis through paracrine mechanisms. Circ Res. 2004;94(5):678-685.

25. Caplan AI, Dennis JE. Mesenchymal stem cells as trophic mediators. $J$ Cell Biochem. 2006;98(5):1076-1084

26. Mirabella T, Cilli M, Carlone S, Cancedda R, Gentili C. Amniotic liquid derived stem cells as reservoir of secreted angiogenic factors capable of stimulating neo-arteriogenesis in an ischemic model. Biomaterials 2011;32(15):3689-3699.

27. Tajiri N, Acosta S, Glover LE, et al. Intravenous grafts of amniotic fluid-derived stem cells induce endogenous cell proliferation and attenuate behavioral deficits in ischemic stroke rats. PLoS One 2012;7(8):e43779.
28. Zhang P, Baxter J, Vinod K, Tulenko TN, Di Muzio PJ. Endothelial differentiation of amniotic fluid-derived stem cells: synergism of biochemical and shear force stimuli. Stem Cells Dev. 2009;18(9): 1299-1308.

29. Matsumoto R, Omura T, Yoshiyama M, et al. Vascular endothelial growth factor-expressing mesenchymal stem cell transplantation for the treatment of acute myocardial infarction. Arterioscler Thromb Vasc Biol. 2005;25(6):1168-1173.

30. Duan HF, Wu CT, Wu DL, et al. Treatment of myocardial ischemia with bone marrow-derived mesenchymal stem cells overexpressing hepatocyte growth factor. Mol Ther. 2003;8(3):467-474.

31. Huang J, Zhang Z, Guo J, et al. Genetic modification of mesenchymal stem cells overexpressing CCR1 increases cell viability, migration, engraftment, and capillary density in the injured myocardium. Circ Res. 2010;106(11):1753-1762.

32. Mangi AA, Noiseux N, Kong D, et al. Mesenchymal stem cells modified with Akt prevent remodeling and restore performance of infarcted hearts. Nat Med. 2003;9(9):1195-1201.

33. Li W, Ma N, Ong LL, et al. Bcl-2 engineered MSCs inhibited apoptosis and improved heart function. Stem Cells. 2007;25(8):2118-2127.

34. Cipriani S, Bonini D, Marchina E, et al. Mesenchymal cells from human amniotic fluid survive and migrate after transplantation into adult rat brain. Cell Biol Int. 2007;31(8):845-850.

35. Kunisaki SM, Fuchs JR, Steigman SA, Fauza DO. A comparative analysis of cartilage engineered from different perinatal mesenchymal progenitor cells. Tissue Eng. 2007;13(11):2633-2644.

36. in 't Anker PS, Scherjon SA, Kleijburg-van der Keur C, et al. Amniotic fluid as a novel source of mesenchymal stem cells for therapeutic transplantation. Blood. 2003;102(4):1548-1549.

37. Magatti M, De Munari S, Vertua E, Gibelli L, Wengler GS, Parolini O. Human amnion mesenchyme harbors cells with allogeneic T-cell suppression and stimulation capabilities. Stem Cells. 2008;26(1): $182-192$.

38. Joo S, Ko IK, Atala A, Yoo JJ, Lee SJ. Amniotic fluid-derived stem cells in regenerative medicine research. Arch Pharm Res. 2012;35(2): 271-280.

39. Chen J, Lu Z, Cheng D, Peng S, Wang H. Isolation and characterization of porcine amniotic fluid-derived multipotent stem cells. PLoS One. 2011;6(5):e19964.

40. Maioli M, Santaniello S, Montella A, et al. Hyaluronan esters drive Smad gene expression and signaling enhancing cardiogenesis in mouse embryonic and human mesenchymal stem cells. PLoS One. 2010;5(11):e15151.

\section{Publish your work in this journal}

Drug Design, Development and Therapy is an international, peerreviewed open-access journal that spans the spectrum of drug design and development through to clinical applications. Clinical outcomes, patient safety, and programs for the development and effective, safe, and sustained use of medicines are a feature of the journal, which

\section{Dovepress}

has also been accepted for indexing on PubMed Central. The manuscript management system is completely online and includes a very quick and fair peer-review system, which is all easy to use. Visit http://www.dovepress.com/testimonials.php to read real quotes from published authors 